\title{
Alternate hot and cold electrodes
}

Zong-Xiong Huang, Sen Yang, Fen-Zeng Yao, Kai-Xuan Xu, Ji-Fang Zhang, Shao-Hua Wu and Jian-Jun Sun*

Ministry of Education Key Laboratory of Analysis and Determination for Food Safety, Fujian Provincial Key Laboratory of Analysis and

Detection for Food Safety, College of Chemistry, Fuzhou University, Fuzhou, 350108, China.

*Corresponding author. Tel.: +86 591 22866135; Fax: +86 591 22866135;

E-mail address: jjsun@fzu.edu.cn.

\begin{abstract}
Alternate hot and cold electrodes, actively heated and chilled, were facilely fabricated for the first time. It consists of two symmetrically placed semiconductor thermoelectric coolers and an embedded interlayer with a Pt-PtRh thermocouple. The tip of Pt-PtRh thermocouple can be used as both an electrochemical electrode and a temperature sensing device simultaneously. Theoretical simulation shows that a local steady-state supercooled water within a radius of ca. $12.6 \mathrm{~mm}$ around the electrode can be obtained. In this paper, the activity of horseradish peroxidase is evidenced at supercooled temperature $\left(-9^{\circ} \mathrm{C}\right)$ in $0.1 \mathrm{M}$ PBS.
\end{abstract}

Keywords: Alternate hot and cold electrode, Supercooled environment, Supercooled electrode, Horseradish peroxidase, Bioactivity.

\section{Introduction}

Since the development by Gründler in 1993 [1-2], temperature modulation electrodes have attracted great interests. A summary of principles and analytical applications of temperature modulation electrodes can be found in reviews [3-7]. There are many advantages for temperature modulation electrodes: affecting thermodynamic and kinetic parameters of the electrode reaction, accelerating the redox reaction rates, and so on [8-11]. In recent years, the cavitation phenomena at 
heated micrometre-sized electrodes have been found and dielectrophoretic and electrothermal effects can be generated on heated disk microelectrodes [12-14].

These electrodes' surface temperature can't be cooled down. For supercooled electrodes (SEs) [15], the electrode surface temperature can be cool down to $-13{ }^{\circ} \mathrm{C}$ in aqueous solution. However, SEs cooled by liquid nitrogen [15] is difficult to operate. Herein, alternate hot and cold electrodes (AHCEs) which based on thermoelectric coolers (TECs) were fabricated. In a Peltier cooler, cooling can be changed to heating simply by reversing the direction of current flowing through the device. AHCEs are convenient to operate because they do not need any refrigerant. Inspired by thermocouple electrodes $[13,18,19]$, we adopted Platinum-Platinum Rhodium (Pt-PtRh) thermocouple as electrode material. The electrode surface temperature in aqueous solution can be easily adjusted from $50{ }^{\circ} \mathrm{C}$ to $-13{ }^{\circ} \mathrm{C}$ by changing the current applied to TECs.

Horseradish peroxidase (HRP) is an important heme-containing enzyme that catalyse the oxidation of a wide variety of electron donor substrates, such as phenols, aromatic amines and iodide [20]. To detect the activity of enzyme in supercooled environment, a simple biosensor for $\mathrm{H}_{2} \mathrm{O}_{2}$ detection was fabricated. 0.1 M Phosphate Buffered Saline (PBS) was adopted in our experiment, because the osmotic pressure of it is very similar to pure normal saline environment. The activity of HRP under supercooled environment has been evidenced.

\section{Materials and methods}

\subsection{Materials}

$\mathrm{Pt}-\mathrm{PtRh}$ thermocouples were obtained from Omega Engineering, Inc. (Stamford CT, 
USA). Horseradish peroxidase was purchased from Shanghai Sangon Biotechnology Co. Ltd. (Shanghai, China). 3-mercaptopropionic acid (MPA) was purchased from Beijing Biosynthesis Technology Co., LTD. Carbodiimide hydrochloride (EDC), N-hydroxysuccinimide (NHS), hydrogen peroxide $\left(\mathrm{H}_{2} \mathrm{O}_{2}\right)$ and hydroquinone (HQ) were purchased from Sinopharm Chemical Reagent Co. Ltd. Potential difference was tested by digital multimeter. NI USB-9211A thermocouple input device was purchased from National Instruments Corporation (Austin, Texas, US). HE 804 thermocouple thermometer was bought from Huato System Co., Ltd. Semiconductor thermoelectric coolers were bought from Xinghe electron Co., Ltd (Suqian, China). The cyclic voltammetry measurements were performed with an electrochemical analyzer (CHI660d, Chenhua, China). Epoxy resin (DEYI) was purchased from Changsha Baxiongdi Adhesive Co. Ltd. Thermal grease (HY810) is a good thermal conducting and insulating material, which was bought from HALNZIYE Co. Ltd.

\subsection{Fabrication of AHCEs}

The fabrication process of AHCEs is shown in Figure 1A. Using the thermal grease, two symmetrically placed TECs were tightly bonded together with Pt-PtRh thermocouple as an embedded interlayer. Then the junction of TECs and the Pt-PtRh thermocouple was coated with epoxy resin. Prior to experiment, AHCEs were polished, and then rinsed with double-distilled water and sonicated before used.

\subsection{Experimental equipment}

The experimental equipment was shown in Figure 1C. An electrochemical cell with a three-electrode configuration was used, with a platinum foil, a saturated calomel electrode as the counter electrode and reference electrode, respectively. The cell was kept in ice-water bath, maintaining the temperature of the bulk solution. Temperature changes of solution around the working electrode, reference electrode and ice-water solution temperature were monitored by thermocouples (T1, T2, T3).

\subsection{Theoretical simulation}

Simulations were carried out using Fluent. It comes from Supercomputing Center of Chinese Academy, which was paid for the computing time. The vertical cross-section with dimensions $9 \mathrm{~cm}$ (horizontal) $\times 9 \mathrm{~cm}$ (vertical) was simulated. The AHCE (radius $150 \mu \mathrm{m}$ ) was placed in the middle of the water's top edge. The 
geometry and meshing were created by GAMBIT modeling and meshing program. The physical data of water were input to Fluent as data tables using published values [21-24]. Because of the low temperature of the supercooled water, laminar flow was assumed as the viscous model. The temperature of AHCE surface was $-9{ }^{\circ} \mathrm{C}$ and boundary conditions (vertical and bottom edge) applied were $2{ }^{\circ} \mathrm{C}$. The value for the heat flux of the top edge is zero. Simulations using the successive substitution solver converged smoothly.

\subsection{Fabrication of the HRP-biosensor}

A carbodiimide coupling reaction involving carbodiimide hydrochloride and $\mathrm{N}$-hydroxysuccinimide is one of the methods employed for coupling carboxylic acid groups containing matrices with enzyme [25-26]. Fabrication procedure of the HRP-biosensor can be summarized as follows. Firstly, as shown in Figure 1B, Pt-PtRh electrodes were plated with gold film (Pt-PtRh/Au electrode). Then Pt-PtRh/Au electrode with $0.30 \mathrm{~mm}$ diameter was polished and washed. Next, the electrodes were electrochemically cleaned in $0.5 \mathrm{M} \mathrm{H}_{2} \mathrm{SO}_{4}$ by potential scanning between $0.2 \mathrm{~V}$ and $1.5 \mathrm{~V}$ for $5 \mathrm{~min}$. Cleaned electrodes were modified by placing them into a $3: 1(\mathrm{v} / \mathrm{v})$ ethanol/water solution containing 0.1 M 3-mercaptopropionic acid (MPA) $12 \mathrm{~h}$. After that, modified electrodes were washed in a 3:1 ethanol/water solution and dried in a nitrogen stream. Finally, the MPA modified electrodes were activated for $6 \mathrm{~h}$ in $0.1 \mathrm{M}$ PBS (pH 7.0) containing 0.2 M EDC, 0.05 M NHS and 2mg/mL HRP.

\section{Results and discussion}

\subsection{Steady supercooled region around AHCEs}

The simulated temperature and velocity vector distribution around the interface of the AHCE in the water at a vertical cross-section through the axis of the cylinder is shown in Figure 2A. The color scale indicates temperature and shows there is a supercooled region with temperature below zero Celsius around AHCE. The Arrows represent velocity vector of the fluid of the natural convection resulted from the temperature difference. And the temperature distribution scale of it is bigger than the heated wire [16-17], which may be cause by the bigger simulation module scale and 
$\underline{\text { smaller temperature difference between boundary conditions. Water rising from }}$ warmer region to colder region in the centre of the region. When water rising up around the electrode surface, it have no space to rise up but spread to the edges. Then two symmetrical vortices are formed below the surface of the AHCE, which is different from the velocity distribution of water around the gold disk electrode [15]. In Figure 2B, the marked shadow representing the supercooled region is restricted within a radius of ca. $12.6 \mathrm{~mm}$ around the AHCE. The velocity distribution around the interface of AHCE and water at a cut plane through the axis of AHCE is shown in Figure 2C. The velocity magnitude may be influenced by two factors: one is temperature and the other is the temperature gradient.

\subsection{Measurement of the temperature of AHCES}

Firstly, Pt-PtRh thermocouples were calibrated by Pt100 thermometer. Secondly, the electrode surface temperature $\left(\mathrm{T}_{E C}\right)$ and the thermocouple entire joint temperature $\left(\mathrm{T}_{T C}\right)$ were compared (Figure 1D inset). The electrode surface temperature was calculated by electrochemistry method and the thermocouple entire joint temperature was calculated by thermocouple thermometer. We use the similar method [27] to detect the potential-temperature coefficient $(\mathrm{PTC})$ of $\mathrm{Fe}(\mathrm{CN})_{6}{ }^{4-} / \mathrm{Fe}(\mathrm{CN})_{6}{ }^{3-}$. The value of PTC is not known when the temperature below 0 degree and $4 \mathrm{M} \mathrm{NaClO}_{4}$ was used as it will not freeze at $-18{ }^{\circ} \mathrm{C}$. The measuring setup is shown in Figure 3A. A millivoltmeter was connected to two Pt-PtRh electrodes putted in the left and right cells, respectively. NI 9211A and HE 804 were adopted to monitor the temperature of two electrodes. As shown in Figure $3 \mathrm{~B}, \Delta \mathrm{T}$ and $\Delta \mathrm{E}$ represent the temperature difference and potential difference of the Pt-PtRh electrodes, respectively. According to $\Delta \mathrm{T}$ and $\Delta \mathrm{E}$, PTC could be obtained in Figure $3 \mathrm{~B}$ inset. PTC of $\mathrm{Fe}(\mathrm{CN})_{6}{ }^{4-} / \mathrm{Fe}(\mathrm{CN})_{6}{ }^{3-}$ in $4 \mathrm{M} \mathrm{NaClO}_{4}$ is deduced as $-1.46 \mathrm{mV} / \mathrm{K}$ through five experimental data. Using PTC, these curves can be converted directly into temperature changes of the electrode/electrolyte interface. The correlation coefficient of $\mathrm{T}_{T C}$ and $\mathrm{T}_{E C}$ is 0.9998 as shown in Figure $3 \mathrm{~B}$ and the relationship between $\mathrm{T}_{T C}$ and $\mathrm{T}_{E C}$ is that: $\mathrm{T}_{T C}=0.02392+1.009 \mathrm{~T}_{E C}$. As temperature is $50{ }^{\circ} \mathrm{C}, \mathrm{T}_{T C}$ and $\mathrm{T}_{E C}$ with the 
max temperature difference $\left(0.5^{\circ} \mathrm{C}\right)$. Therefore, the consistence between $\mathrm{T}_{E C}$ and $\mathrm{T}_{T C}$ was verified perfectly.

\subsection{The performance of AHCEs}

The temperature of electrodes can be adjusted from ca. $-13{ }^{\circ} \mathrm{C}$ to $50{ }^{\circ} \mathrm{C}$ as shown in Figure 4A. The cyclic voltammogram of $\mathrm{Fe}(\mathrm{CN}) 66^{4-} / \mathrm{Fe}(\mathrm{CN}) 66^{3-}$ in $0.5 \mathrm{M} \mathrm{KCl}$ aqueous solution still be obtained in Figure 4A inset as the temperature dropped to $-13^{\circ} \mathrm{C}$. The performance of AHCEs was shown in Figure 4B. The temperature of AHCEs can be heated up or cooled down easily. The thermal stability was tested by using different currents applied to TECs. At same current, good stability and reproducibility can be obtained. A new temperature platform can be achieved in a relatively short period of time $(20 \mathrm{~s} \sim 30 \mathrm{~s})$ by modulating currents.

\subsection{The electrochemical behavior of horseradish peroxidase in supercooled water}

CVs of HRP electrode (Au/MPA/HRP) in $0.1 \mathrm{M}$ PBS containing $1 \mathrm{mM}$ HQ and 1 $\mathrm{mM} \mathrm{H} \mathrm{H}_{2}$ at different temperature were shown in Figure 4C. The electrochemical reaction of HQ was inhibited by HRP for the blank solution at $-9{ }^{\circ} \mathrm{C}$. The peak current of $\mathrm{HQ}$ decrease and the peak current of $\mathrm{H}_{2} \mathrm{O}_{2}$ increase while adding $1 \mathrm{mM}$ $\underline{\mathrm{H}}_{2} \mathrm{O}_{2}$. It shows that HRP still has the capability of catalyzing the reaction of hydrogen peroxide under supercooled environment. As temperature of electrode heated up from $-9{ }^{\circ} \mathrm{C}$ to $50{ }^{\circ} \mathrm{C}$, the peak current of $\mathrm{H}_{2} \mathrm{O}_{2}$ increased, indicating the increase of the activity of HRP (Figure 4C. Inset).

\section{Conclusions}

In summary, AHCEs with high accuracy and thermal stability were successfully fabricated. The electrode temperature can be regulated from ca. $-13{ }^{\circ} \mathrm{C}$ to $50{ }^{\circ} \mathrm{C}$ in aqueous solution. The electrochemical experiment and temperature measurement can be taken at the same time. Compared with supercooled electrodes cooled by liquid nitrogen, AHCEs have longer working hours and do not need any refrigerant. Theoretical simulation shows that a local steady-state supercooled water within a radius of ca. $12.6 \mathrm{~mm}$ around the electrode can be obtained. In addition, the sensing of HRP under supercooled 
aqueous environment $\left(-9^{\circ} \mathrm{C}\right)$ has been achieved.

\section{Acknowledgments}

This work is financially supported from the National Science Foundation of China (Nos. 21275030 and 21475032), National Basic Research Program of China (No.2010CB732403), and Program for Changjiang Scholars and Innovative Research Team in University (No. IRT1116).

\section{References}

[1] P. Gründler, T. Zerihun, A. Möller, A. Kirbs, J. Electroanal. Chem. 360 (1993) $309-314$.

[2] T. Zerihun, P. Gründler, J. Electroanal. Chem. 404 (1996) 243-248.

[3] G. G. Wildgoose, D. Giovanelli, N. S. Lawrence, R. G. Compton, Electroanalysis 16 (2004) 421-433.

[4] P. Gründler, G.-U. Flechsig, Microchimica Acta 154 (2006) 175-189.

[5] P. Gründler, A. Kirbs, L. Dunsch, ChemPhysChem 10 (2009) 1722-1746.

[6] I. J. Cutress, F. Marken, R. G. Compton, Electroanalysis 21 (2009) 113-123.

[7] G. U. Flechsig, A. Walter, Electroanalysis 24 (2012) 23-31.

[8] J. Wang, P. Gründler, G.-U. Flechsig, M. Jasinski, G. Rivas, E. Sahlin, J. L. Lopez Paz, Anal. Chem. 72 (2000) 3752-3756.

[9] Y.-C.Tsai, B. A.Coles, R. G. Compton, F. Marken, J. Amer. Chem. Soc. 124 (2002) 9784-9788.

[10] H. Wei, J. J. Sun, L. Guo, X. Li, G. N. Chen, Chem. Comm. 20 (2009) $2842-2844$.

[11] A. Walter, A.-E. Surkus, G.-U. Flechsig, Anal. Bioanal. Chem. 405 (2013) 3907-3911.

[12] L. Rassaei, M. Nebel, N. V. Rees, R. G. Compton, W. Schuhmann, F. Marken, Chem. Comm. 46 (2010) 812-814.

[13] A. Boika, A. S. Baranski, Anal Chem. 80 (2008) 7392-7400.

[14] A. S. Baranski, A. Boika, Anal. Chem. 84 (2011) 1353-1359.

[15] Z. X. Huang, S. Yang, J. W. Guo, S. H. Wu, J. J. Sun, G. N. Chen, Electrochem. 
Comm. 48 (2014) 107-110.

[16] A. Beckmann, B. A. Coles, R. G. Compton, P. Grundler, F. Marken, A. Neudeck, J. Phys. Chem. B 104 (2000) 764-769.

[17] P. Grundler, Fresen. J. Anal. Chem. 367 (2000) 324-328.

[18] A. S. Baranski, A. Boika, Anal. Chem. 82 (2010) 8137-8145.

[19] H. Zhang, X. Xiao, T. Su, X. Gu, T. Jin, L. Du, J. Tang, Electrochem. Comm. 47 (2014) 71-74.

[20] N. C. Veitch, Phytochemistry 65 (2004) 249-259.

[21] D. R. Lide, Handbook of Chemistry and Physics, 90th ed. Boca Raton, Florida, 2009.

[22] C. Angell, J. Shuppert, J. Tucker, J. Phys. Chem. 77 (1973) 3092-3099.

[23] O. Benchikh, D. Fournier, A. Boccara, J. Teixeira, J. Phys. 46 (1985) 727-731.

[24] J. Hallett, Proc. Phys. Soc. 82 (1963) 1046.

[25] E. Kim, K. Kim, H. Yang, Y. T. Kim, J. Kwak, Anal. Chem. 75 (2003) $5665-5672$.

[26] M. Delvauxa, A. Walcarius, S. Demoustier-Champagne, Anal. Chim. Acta 525 (2004), 221-230.

[27] J. L. Valdes, B. Miller, J. Phys. Chem. 92 (1988), 525-532.

\section{Captions}

Figure 1. (A) The fabrication process of AHCEs. SC represents semiconductor. (B) The photograph of Pt-PtRh (1) and Pt-PtRh/Au electrode surface (2). (C) The experiment setup, W, R, C represents the working electrode, reference electrode and counter electrode, respectively. T1, T2, T3 represent copper-constantan temperature measuring probes. (D) The comparison of the temperature monitored by Pt-PtRh thermocouple $\left(\mathrm{T}_{T C}\right)$ and the temperature monitored by electrochemical method $\left(\mathrm{T}_{E C}\right)$, Inset: The different measuring regions of $\mathrm{T}_{T C}$ and $\mathrm{T}_{E C}$.

Figure 2. (A) Simulated temperature and velocity vector distribution around the 
interface of the AHCE and water at a vertical cross-section through the axis of the cylinder. Arrows represent the velocity vector and the magnitude of velocity is represented by the length of the arrow. (B) Temperature profile along the axle wire of AHCE. The dashed area represents the supercooled zone. (C) The magnitude of velocity along the axle wire of electrode. Ambient temperature: $2{ }^{\circ} \mathrm{C}, \mathrm{T}_{A H C E}=-9{ }^{\circ} \mathrm{C}$.

Figure 3. (A) The experimental setup for detection of potential-temperature coefficient, (1) electrode 1, (2) electrode 2, (3) beaker, (4) electrochemical cell, (5) 0.5 $\mathrm{mM} \mathrm{Fe}(\mathrm{CN})_{6}{ }^{4-} / \mathrm{Fe}(\mathrm{CN})_{6}{ }^{3^{-}}+4 \mathrm{M} \mathrm{NaClO}_{4}$ aqueous solution, (6) insulating foam, (7) 4 $\mathrm{M} \mathrm{NaClO}_{4}$ aqueous solution, (8) heater, (9) refrigerator. (B) Temperature difference $(\Delta \mathrm{T})$-Time curve and potential difference $(\Delta \mathrm{E})$-Time curve of two Pt-PtRh thermocouple electrodes, Inset: The linear relationship between $\Delta \mathrm{T}$ and $\Delta \mathrm{E}$.

Figure 4. (A) and (B) Temperature-time curve of AHCEs, $-0.6 \mathrm{~A} \sim 0.6 \mathrm{~A}$ represent different currents applied to TECs. (A) Inset: Cyclic voltammograms in $5 \mathrm{mM}$ $\mathrm{Fe}(\mathrm{CN}) 6^{4-} / \mathrm{Fe}(\mathrm{CN}) 6^{3^{-}}+0.5 \mathrm{M} \mathrm{KCl}$ aqueous solution. (B) Inset: Hot and cold state of AHCEs. (C) CVs of Au/MPA/HRP in 0.1M PBS (pH 7.0) containing $1 \mathrm{mM}$ HQ and $1 \mathrm{mM} \mathrm{H}_{2} \mathrm{O}_{2}$ at different temperature, blank solution: 0.1 M PBS containing $1 \mathrm{mM} \mathrm{HQ}$, Scan rate: $100 \mathrm{mV} / \mathrm{s}$. Inset: Peak current $\Delta i$ (deduction of blank) at different temperature.

\section{Figures}



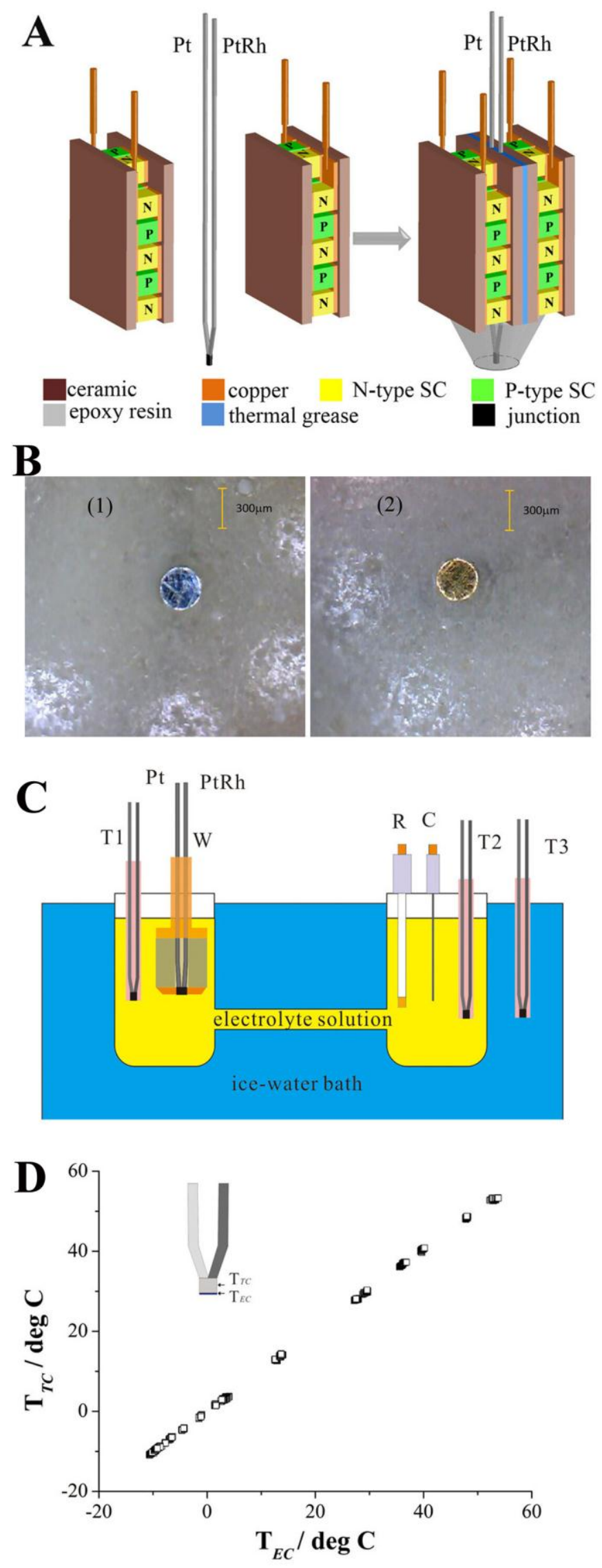

Figure 1. 

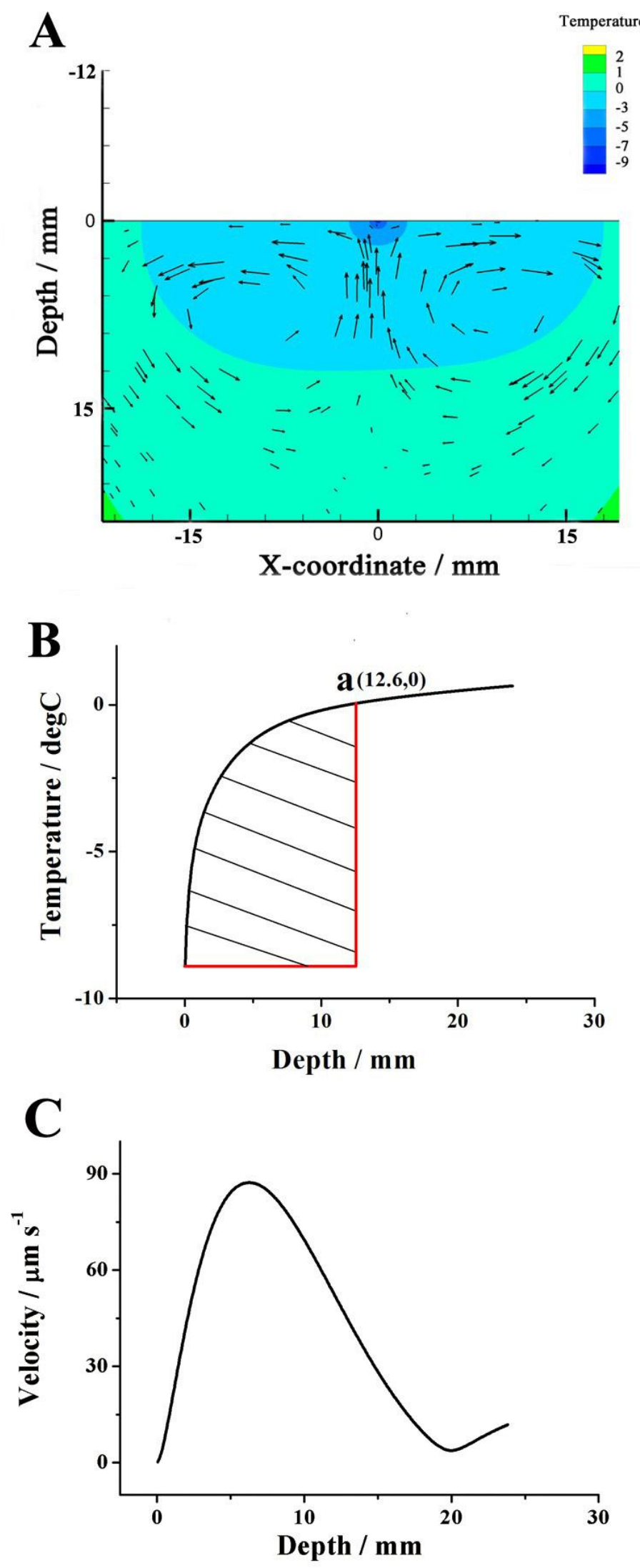

Figure 2 


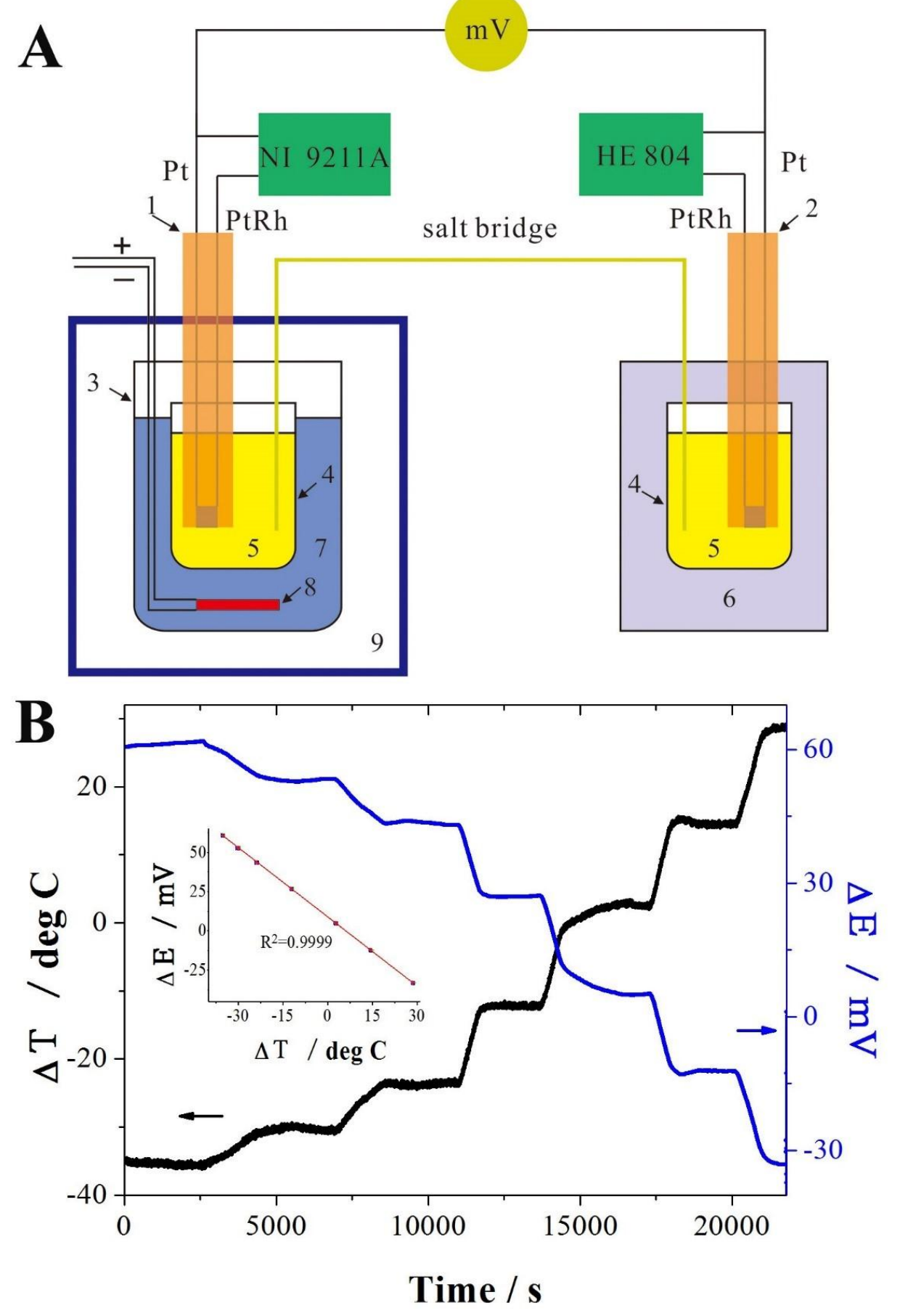

Figure 3 


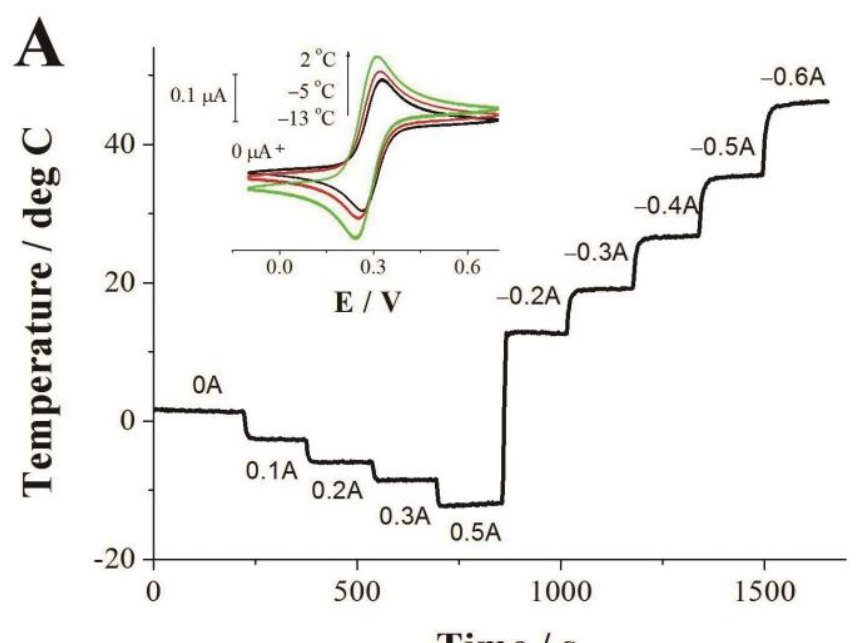

Time / s

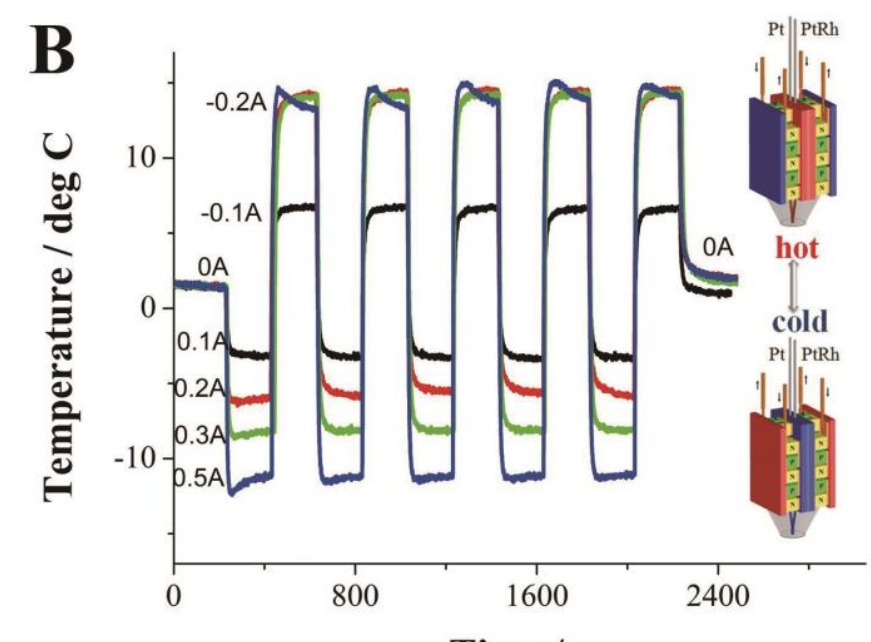

Time / s

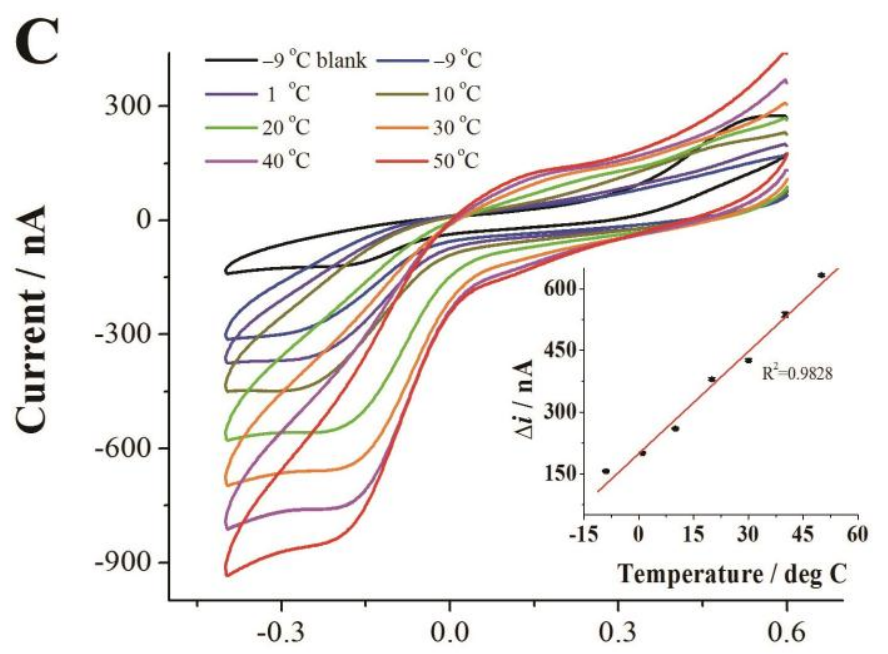

Potential / V

Figure 4 


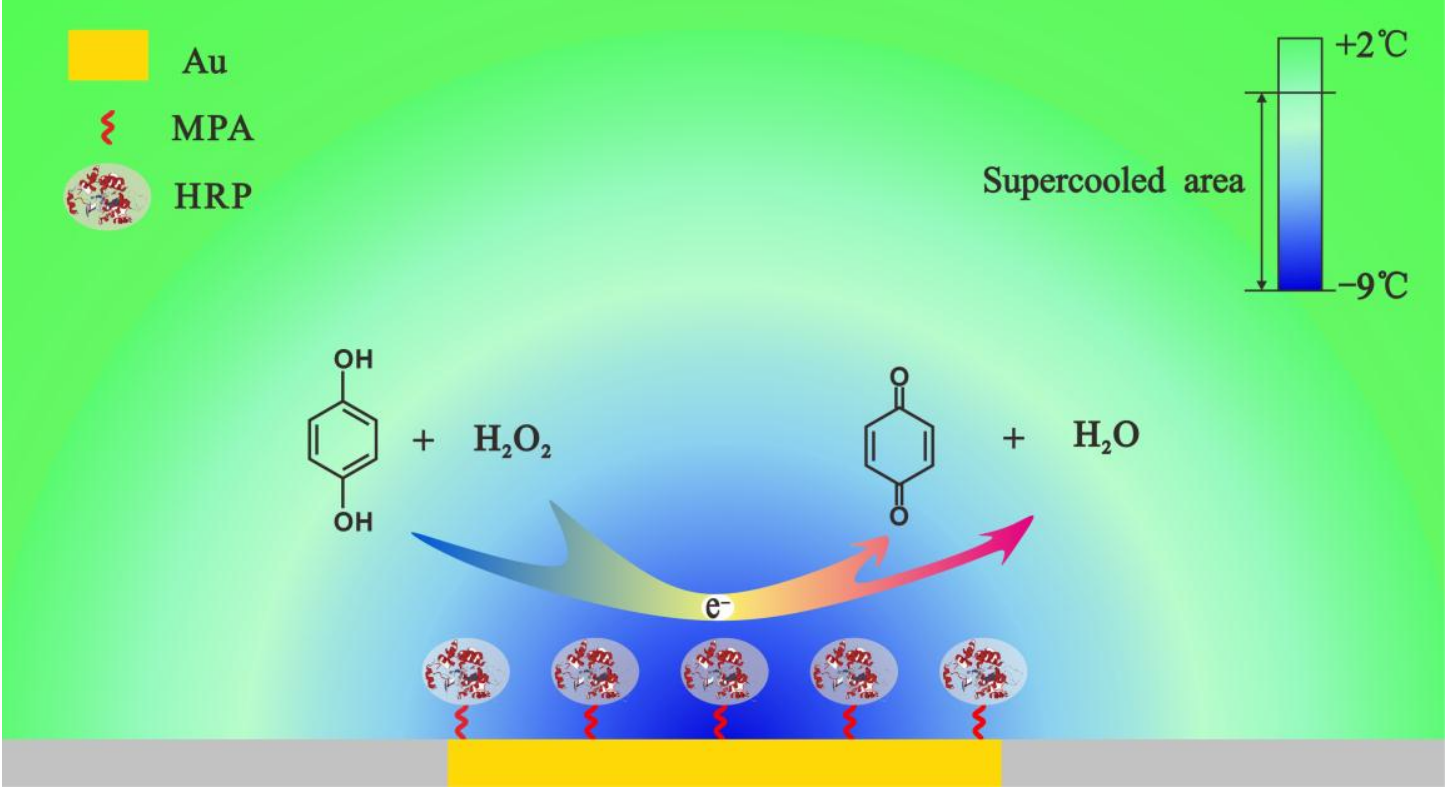

